\title{
Patrimonialização, território usado e processo de registro da feira livre de domingo de Alfenas (MG) como bem cultural imaterial do município
}

\author{
Patrimonialization, used land, and registration process of the Sunday open-air fair in Alfenas \\ (MG) as an immaterial cultural good of the municipality
}

\author{
Gil Carlos Silveira Porto \\ Doutor em Geografia - Docente do Curso de Graduação e \\ Pós-graduação em Geografia da Unifal-MG, Brasil \\ gil.porto@unifal-mg.edu.br
}

\begin{abstract}
Resumo
O presente texto é um ensaio geográfico que busca explicar o processo de patrimonialização da feira livre de domingo de Alfenas (MG) considerando o conceito de território usado. Para tanto, discorreu-se inicialmente sobre o conceito de feira livre, para em seguida apresentar uma breve recomposição de sua origem enquanto atividade de diferentes grupos. Após a composição desse quadro conceitual e genético, foram apresentados processos de registro de feiras no Brasil, como parte do processo de patrimonialização global, ao qual se insere o registro da feira de Alfenas como bem cultural intangível, ocorrido em 2019. Em seguida, buscou-se abordar a feira livre como território usado, bem como lugar constituído por feirantes, consumidores e frequentadores e apontar significados construídos com o processo de registro. Para a construção deste texto foram consultados livros, artigos, dossiês e outros documentos que possibilitaram caracterizar o fenômeno e operacionalizá-lo a partir de conceitos geográficas. Pretendeu-se com a discussão produzida valorizar a dimensão espacial das feiras livres, discutir a possibilidade de que outras feiras brasileiras se tornem patrimônios imateriais culturais e contribuir para ampliação de políticas do governo voltadas para a preservação do patrimônio cultural.
\end{abstract}

Palavras-chave: Feiras Livres; Território Usado; Constituição de Lugares; Patrimônio Imaterial; Alfenas (MG).

\begin{abstract}
This text is a geographical essay that seeks to explain the patrimonialization process of the Sunday open-air fair in Alfenas (MG), considering the concept of used territory. Therefore, the concept of an open-air fair was initially discussed. Then a brief re-composition of its origins as an activity of different groups were presented. After the composition of this conceptual and genetic framework, processes for registering fairs in Brazil were presented as part of the global patrimonialization process, which includes registering the open-air fair in Alfenas as an immaterial cultural good that took place in 2019. To approach the open-air fair as a used territory and a place made up of market vendors, consumers, and regulars, and to point out meanings constructed with the registration process. For the construction of this text, books, articles, dossiers, and other documents were consulted that made it possible to characterize the phenomenon and operationalize it from geographical concepts. It was intended with the discussion produced to value the spatial dimension of open-air fairs, discuss the possibility that other Brazilian fairs become immaterial cultural patrimonies and contribute to the expansion of government policies aimed at preserving cultural heritage.
\end{abstract}

Keywords: Open-air Fairs; Used Land; Constitution of Places; Immaterial Patrimony; Alfenas (MG). 


\section{INTRODUÇÃO}

A forma de comércio que se estabelece nas feiras livres é uma das atividades humanas que marcam a formação socioespacial brasileira. As feiras foram, por mais de dois séculos, a principal fonte de abastecimento para a maioria da população do país. A partir da segunda metade do século XX esses mercados periódicos passam a concorrer com lojas de supermercados, no entanto continuam resistindo às formas modernas de comercialização. Em função de seu conteúdo espacial, histórico, econômico e cultural, têm se tornado bens imateriais de alguns municípios brasileiros. Esse processo é uma prática pouco comum no Brasil, mas o tema vem sendo discutido por diferentes grupos e instituições. Nesse contexto se insere a feira livre de domingo de Alfenas (MG), que se tornou patrimônio cultural imaterial do município em 2019.

A patrimonialização global é um fenômeno controverso nos países da periferia do sistema capitalista, pois, à medida que se manifesta nos lugares ao selecionar frações de cidades para a preservação, não constitui ações efetivas para a promoção da qualidade de vida de moradores dessas cidades, ampliando às vezes as desigualdades socioespaciais já existentes. Como parte da política de governos em diferentes escalas de gestão, além de anunciar a necessidade de preservar a história e a memória, o processo de patrimonialização gera contradições, entre elas a mercantilização da terra urbana, que promove a saída de moradores de áreas tombadas.

É nesse contexto que surgem em cidades brasileiras experiências de registro de feiras como patrimônios culturais imateriais nacionais ou dos municípios onde se localizam. Desde 2006, pelo menos quatro feiras brasileiras foram registradas como bens culturais imateriais (Caruaru [PE], Campina Grande [PB], Capelinha [MG] e Alfenas [MG]), além da feira de São Joaquim, em Salvador (BA), que aguarda decisão do Instituto do Patrimônio Histórico e Artístico Nacional (IFHAN) quanto ao pedido de registro. Cabe ressaltar que as feiras livres de Capelinha e Alfenas foram registradas como bens imateriais municipais.

Quanto às possibilidades de estudo do fenômeno da patrimonialização a partir de conceitos e categorias da Geografia, identificamos pelo menos três caminhos.

O primeiro, que nos inquieta bastante, embora não seja percurso proposto neste escrito, é saber se há possibilidade de caracterizar as feiras livres como rugosidades, conceito elaborado por Santos (2006), uma vez que as feiras são eventos periódicos, cuja materialidade que a hospeda ou que dela faz parte, se "dissolve" com o seu término no começo ou no final da tarde ou ao final do dia. Para o referido autor, as rugosidades são heranças físico-territoriais, socioterritoriais ou sociogeográficas.

Uma segunda perspectiva, relacionada à anterior, mas que será discutida com superficialidade no presente texto, é aquela que identifica a patrimonialização de feiras como 
possibilidade de permanência de rugosidades e do conteúdo que lhes é próprio nas localidades onde são registradas. Nesse tipo de abordagem, o registro de feiras é analisado considerando-se, sobretudo, a noção de preservação.

A última possibilidade, a que abordaremos aqui, analisa o registo de feiras a partir dos conceitos de território usado e lugar (constituição de lugares). Consideramos que o território de qualquer país é usado por diferentes organizações e agentes. Entre as primeiras citamos empresas, instituições financeiras, outras unidades produtivas, e entre os agentes listamos mulheres e homens que, a partir do uso individual ou coletivo do território, constituem lugares por meio de relações horizontais estabelecidas entre si.

Desse modo, as feiras livres são produzidas a partir do uso do território nacional por feirantes, consumidores, transeuntes e estratos demográficos advindos em sua maioria das classes populares, que, ao serem interpretadas à luz de diferentes áreas do conhecimento, são objetos de conceituação, processo que envolve também o conhecimento de suas origens.

\section{FEIRAS LIVRES: BREVE DEFINIÇÃO E ORIGEM}

As feiras livres são uma forma de comércio periódico não moderna e predominantemente varejista. São frequentadas por consumidores e pessoas de diferentes classes sociais, embora seus usuários pertençam, sobretudo, às classes sociais menos favorecidas economicamente. Segundo Porto (2005), as feiras constituem práticas humanas que ocorrem desde a formação de sociedades em escalas temporais e espaciais específicas e distintas, e vem se adequando e resistindo às transformações ocorridas nas formas de comércio. Resultam da necessidade de compra e venda de produtos diversos e integram um conjunto de valores e práticas de seus utentes.

Cabe acrescentar ainda que esses eventos periódicos são práticas econômicas, culturais e espaciais e decorrem do interesse coletivo, ao mesmo tempo que refletem a forma como o modo de produção capitalista produz e condiciona usos distintos do território urbano. As feiras estão inseridas numa totalidade socioespacial e econômica e estão sempre se movimentando, ao mesmo tempo que integram o espaço banal de parte considerável das cidades brasileiras.

A expressão feira ainda tem sido usada para designar um “[...] sítio geográfico - a praça do mercado - com atribuições sociais, econômicas, culturais, políticas etc., onde um certo número concreto de compradores e vendedores se reúnem com a finalidade de trocar ou vender e comprar bens e mercadorias” (MOTT, 1975, p. 10, apud SANTOS, p. 2007). Uma outra definição de feiras foi elaborada por Ferreti (2000), que ao estudar esse tipo de comércio no Nordeste brasileiro as caracterizou como reuniões comerciais periódicas que ocorrem em local descoberto (ruas e praças, 
por exemplo), frequentemente no entorno de mercados, estruturas físicas que geralmente são construídas pelos governos municipais.

As feiras também podem ser identificadas como parte do circuito inferior da economia urbana tais como foram estudadas por Jesus (1992), Costa (2003), Porto (2005, 2007), Trevisan (2008), Santos (2017), entre outros estudiosos que vem discutindo esse evento a partir da teoria dos dois circuitos da economia urbana (SANTOS, 2008). De maneira geral, a partir dessa teoria, concebemos as feiras como

[...] elementos do circuito inferior da economia urbana, mas relacionados ao circuito superior, sobretudo às formas de comércio e serviços (supermercados e bancos, por exemplo), presentes nas cidades onde ocorrem, uma vez que, não sendo atividades hegemônicas, são uma contra-racionalidade, uma contrafinalidade do espaço total capitalista, cuja marca principal é a prevalência das horizontalidades do lugar, marcada por uma racionalidade própria, com objetivos e dinâmica socioespacial, com fluxos e circulação a partir de onde se inserem e/ou ocorrem". (SANTOS, 2017, p. 49)

No que se refere à origem das feiras livres, é provável que o embrião dessa forma de comércio tenha existido pelo menos desde 2000 a. C. e se desenvolveu em praças abertas e em pontos de venda cobertos distribuídos em lados de ruas (MUMFORD, 2012) destinadas a essa finalidade. Desse modo, é possível afirmar que as feiras livres são eventos seculares e sua origem está associada à necessidade de trocas do excedente da produção por parte de produtores, bem como à aquisição daquilo que não era produzido.

Ou seja, essas pequenas assembleias, conforme afirma Pirenne (1963), consistiam em suprir necessidades econômicas da população da região e certamente satisfazer ao desejo de sociabilidade, inerente a todos os homens e mulheres. Esse autor ainda afirma que, mesmo em função de uma crise comercial ocorrida na Europa no século IX, havia ali muitos pequenos mercados semanais, onde camponeses dos arredores comercializavam ovos, frangos, lã ou tecido.

Há registro de que em Portugal as feiras existem desde os séculos XIII/XIV, quando D. Dinis, rei de Portugal e do Algarve, determinou a criação de uma feira anual na vila de Santarém, com duração entre primeiro de abril e primeiro de junho (FREITAS, 1977).

No Brasil, sabe-se que desde o período colonial a Coroa Portuguesa ensaiou estabelecer essa atividade com o intuito de adquirir, por meio do trabalho forçado de populações que compunham povos originários, produtos extraídos da natureza de interesse de comerciantes e integrantes da Monarquia portuguesa e da Igreja. No entanto, somente no Setecentos as feiras livres passam a ocorrer em lugarejos com uma incipiente vida protourbana, associada ao crescimento populacional e à diversificação da atividade econômica (MOTT, 1976; PORTO, 2018). O tênue uso do território por esse tipo de atividade pode ser considerado também um resultado de sucessivas transformações do meio natural em um meio mais regido pela incipiente técnica, como a advinda da criação de uma rede mais densa de caminhos e estradas. 
Um exemplo que configura essas transformações foi o surgimento das feiras de gado, como a de Capuame, conhecida como a primeira feira de gado na América portuguesa, que existiu entre o século XVII e o início do século XIX e se situava em algum ponto entre os municípios de Camaçari e Dias D’Ávila (BA) (HENRIQUE, 2014; PORTO, 2018). De acordo com Mott (1976), no Setecentos há registro de feiras livres nas localidades de Mata de São João e Vila de Nazareth (província da Bahia), assim como nas povoações de Goiana (Pernambuco) e Laranjeiras (Sergipe).

Outras feiras que merecem destaque, ocorridas entre os séculos XVII e XIX, foram as feiras de burros de Sorocaba, realizadas no entorno da cidade, "em meio das invernadas onde pastavam as tropas" (DEFFONTAINES, 1935), pois ocorriam entre os meses de maio e julho. Não se sabe ao certo a data de surgimento dessas feiras, mas especula-se que tenham ocorrido entre 1750 e 1766 e mantiveram centralidade na vida econômica da Colônia, e depois do Império, até a segunda metade do século XIX, quando a venda de muares caiu significativamente por conta da crise do tropeirismo e do advento da ferrovia na região (STRAFORINI et al., 1998).

Se por um lado as feiras de muares de Sorocaba tiveram o seu fim decretado por conta da chegada da ferrovia à localidade, por outro, feiras livres de periodicidade distinta foram criadas ou fortalecidas em função da facilidade de comunicação que se estabelecia entre localidades atendidas por linhas férreas e pela ampliação de vilas e cidades nas diferentes unidades da Federação entre o final do século XIX e a primeira metade do século passado. Ou seja, à medida que se densificam as redes de comunicação entre lugarejos, vilas e cidades, bem como o acesso da população rural a essas localidades, as feiras passam a estar presentes no cotidiano de um grupo cada vez maior de brasileiros.

No caso do Sul de Minas, há registro de feiras livres, como a feira de gado do município de Três Corações, regulamentada pelo Estado a partir de 1898, mas que ganha visibilidade regional nas duas primeiras décadas do século XX (SAES \& ROSA, 2013). A ferrovia que chega à localidade em 1884 pode ser considerada como evento crucial para ampliar a comercialização de gado na feira acima citada.

Via de regra, além dessa feira é provável que formas embrionárias dessa modalidade de comércio tenham surgido em outras localidades sul-mineiras desde o final do século XIX. No entanto, o não registro desses eventos em relatórios de prefeituras e câmaras municipais constitui-se num obstáculo para a sua recomposição. Analisadas em conjunto, as feiras de outros Estados e regiões podem contribuir para o entendimento da formação socioespacial brasileira.

Passados mais de dois séculos após o surgimento das primeiras feiras livres, elas estão presentes em mais de 20\% dos municípios brasileiros. Em 2015 foram registradas no país 5.119 feiras livres em 1.176 municípios, a maioria delas (83\%) com periodicidade semanal. Foram 
também contabilizadas 1.331 feiras agroecológicas ou com produção orgânica em 624 municípios (MINISTÉRIO DO DESENVOLVIMENTO SOCIAL E COMBATE À FOME, 2015).

Desse conjunto de feiras, um pequeno número se tornou ou está em via de se tornar patrimônio cultural imaterial do Brasil, como as feiras livres de Caruaru (PE), Campina Grande (PB) e Salvador (BA), ou patrimônio cultural imaterial municipal, como as feiras livres de Capelinha e Alfenas $(\mathrm{MG})^{1}$. Esses processos, embora ocorram de forma isolada, precisam ser interpretados em sua relação com o processo de patrimonialização global.

\section{PATRIMONIALIZAÇÃO GLOBAL, LOCAL E IMATERIAL}

A discussão proposta neste tópico ainda não foi desenvolvida a contento na Geografia brasileira, embora existam trabalhos que nos auxiliam nesta discussão introdutória. Entre os estudos que elegemos como base, destacam-se Costa (2015), que corrobora na construção de uma interpretação dialética da patrimonialização, caracterizada pelo autor como patrimonialização global, onde, a título de exemplo, cidades históricas são consideradas totalidades urbanas inseridas na "totalidade-mundo" (SANTOS, 2006) e Souza (2019), que propõe, a partir da operacionalização de conceitos como território usado, rugosidades, paisagem e lugar, teorizar sobre a preservação do patrimônio público.

A patrimonialização global pode ser entendida como um movimento mundial contemporâneo que busca preservar patrimônios urbano e natural, mas que se expressa com maior visibilidade na inscrição de cidades distribuídas em toda a Terra na Lista de Patrimônios da Organização das Nações Unidas para a Educação, a Ciência e a Cultura (UNESCO) "ante a corrida pela mercantilização dos lugares por parte das governanças urbanas” (COSTA, 2015, p. 25).

Além do processo de mercantilização da terra urbana e de objetos que compõem a estrutura interna das cidades e das contradições daí advindas, a patrimonialização resulta também de necessidades que vêm surgindo nas últimas décadas de revalorização do velho e do antigo, bem como da recomposição de paisagens nas cidades em diferentes continentes e que no Brasil se expressam, a título de exemplo, em frações de cidades como Diamantina, Belo Horizonte, Salvador, Olinda, entre outras.

O processo de patrimonialização global exposto acima se refere ao tombamento de edificações situadas isoladamente ou agrupadas em frações das cidades em questão. No entanto, há um grupo de bens que, embora necessitem de homens, mulheres e objetos geográficos para se manifestarem, não possuem materialidade fixa, como santuários, igrejas, prédios, casarões e demais

\footnotetext{
${ }^{1}$ Há o caso emblemático, que não será discutido aqui, da feira livre de Dourados (MS), que foi "tombada" como patrimônio histórico-cultural do município em 2010. Emblemático porque as feiras como bens culturais imateriais não podem ser tombadas (processo que envolve edificações), nem removidas, processo ocorrido com a referida feira em 2018 (LARA, 2018).
} 
edificações que se tornaram patrimônios. Trata-se de patrimônios culturais intangíveis, que se inserem num processo de patrimonialização global imaterial.

Em relação ao patrimônio imaterial da humanidade, seu assentimento pela UNESCO é mais recente e ocorre desde meados dos anos 2000, que a partir de então tem incentivado o registro de bens imateriais de diferentes grupos societários que formam um amálgama de manifestações culturais. Esse organismo adotou em 2003 uma Convenção sobre a Salvaguarda do Patrimônio Cultural Intangível ou Imaterial, estabelecendo os principais instrumentos das políticas de governo que envolvem o patrimônio cultural intangível (PELEGRINI \& FUNARI, 2008), originado, no caso do Brasil, em diferentes fases da sua formação socioespacial.

Assim, o patrimônio cultural imaterial abarca hodiernamente manifestações intangíveis de grupos de distintas classes sociais, impossíveis de serem tocadas, mas percebidas, bens distintos da cultura material, que compreende artefatos e o que é transformado ao longo do tempo (PELEGRINI \& FUNARI, 2008). De maneira geral, os bens intangíveis se manifestam em tradições e expressões orais, expressões artísticas, práticas sociais, rituais e atos festivos, conhecimentos e práticas relacionadas com a natureza e o universo e técnicas artesanais tradicionais (CONVENÇÃO PARA A SALVAGUARDA DO PATRIMÔNIO CULTURAL IMATERIAL, 2003, p. 5; PELEGRINI \& FUNARI, 2008, p. 48).

No Brasil, mais de uma dezena de bens já foi registrada como patrimônios culturais desde 2002, ano de inscrição dos primeiros bens. Esses bens subdividem-se em:

1. rituais e festas que balizam as vivências coletivas e outras práticas da vida social, como religiosidades e entretenimento;

2. manifestações artísticas em geral que envolvem linguagens, danças e ritmos;

3. lugares onde são reproduzidas práticas culturais coletivas, como mercados, feiras, santuários ou praças;

4. modos de fazer e conhecimentos radicados no cotidiano das comunidades (PELEGRINI \& FUNARI, 2003, p. 73).

Como se mencionou acima, bens culturais intangíveis têm sido registrados no Basil como patrimônios desde 2002, processo que ocorre após reconhecimento de que possuem valores histórico-culturais peculiares reconhecidos pela sociedade onde estão inseridos. Esse processo é feito pelo IFHAN, nos casos em que a solicitação é para que o bem se torne patrimônio nacional, e no caso de registro desse bem nos municípios a decisão final cabe ao representante do Poder Executivo municipal. Nos dois casos, o processo de patrimonialização de feiras livres, objeto de análise deste ensaio, envolve a participação de diferentes segmentos da sociedade civil e o conhecimento do bem que se deseja registrar, pois, como observa Araújo (2011, p. 492), "Não se preserva algo que não se conhece. Neste sentido, para documentar o bem cultural e melhor conhecêlo [...]". Como parte do processo de conhecimento desse bem pela comunidade na qual está 
inserido, há necessidade de produzir dossiês e outros documentos que explicitem a sua origem, permanência no tempo e as múltiplas relevâncias que possuem.

\section{FEIRAS LIVRES BRASILEIRAS PATRIMONIALIZADAS}

Como mencionado acima, há no Brasil duas feiras que já se tornaram patrimônios culturais imateriais do Brasil (Caruaru e Campina Grande), uma terceira que está em via de ser registrada (a feira de São Joaquim em Salvador) e outras duas que já foram registradas como bens culturais imateriais municipais (feiras de Capelinha e a feira de domingo de Alfenas).

A seguir discorreremos de maneira resumida sobre o processo de registro dessas feiras, visando contribuir para o entendimento de como se dá esse procedimento e quem são os sujeitos envolvidos, buscando também conhecer suas características gerais.

A primeira feira livre brasileira a se tornar patrimônio imaterial do Brasil foi a feira de Caruaru (PE), ao ser registrada como bem imaterial no Livro de Registro dos Lugares. A referida feira existe desde o final do Setecentos e sua origem se confunde com o início de formação da cidade de Caruaru. Desde seu surgimento até 1992, a feira se realizava na área central da cidade, sendo então removida para o Parque 18 de Maio, antigo Campo de Monta, onde havia mais espaço para atendimento de um maior número de consumidores ${ }^{2}$. A feira de Caruaru é formada por um conjunto de feiras. Pode-se afirmar que há muitas feiras dentro da feira: feira de gado, feira de ervas e raízes medicinais, feira de fumo, feira de flores e plantas ornamentais, feira de ferragens, feira do troca-troca, feira de culinária, feira de frutas e verduras etc. (ARAÚJO, 2011, p. 494).

A feira de Caruaru foi gravada no Livro de Registro dos Lugares em 2006, após a Prefeitura Municipal encaminhar pedido ao presidente do IPHAN solicitando seu registro como patrimônio nacional. Esse pedido foi acompanhado pela documentação necessária à abertura de processo administrativo e por depoimentos e manifestações de diferentes instituições locais, como a Diocese de Caruaru e a Academia Caruaruense de Cultura, Ciências e Letras, entre outras (ARAÚJO, 2011). Cabe ainda ressaltar que o processo de registro dessa feira foi o mais rápido se comparado aos pedidos referentes às demais, em atendimento ao disposto no Decreto 3.551/2000, de que os bens registrados como imateriais precisam passar por nova avaliação pelo menos a cada dez anos. A Feira de Caruaru foi revalidada como patrimônio cultural do Brasil pelo IPHAN em 22 de julho de 2021, processo que deverá ocorrer em relação às demais feiras.

De forma semelhante à feira descrita anteriormente, a iniciativa de solicitar ao IPHAN o registro da feira de Campina Grande partiu da Prefeitura Municipal em 2007, tendo a participação de instituições públicas e privadas parceiras (ARAÚJO, 2011). A mobilização para a efetivação do

\footnotetext{
${ }^{2}$ A transferência da feira ampliou o número de feirantes de 5 mil em 1970 para 28 mil em 2004, havendo assim um crescimento de 500\% (IFHAN, 2006).
} 
registro ocorreu a partir de representantes de diferentes grupos, como pesquisadores, professores, ativistas, feirantes e consumidores. Dez anos após o pedido, a feira foi inscrita pelo IPHAN no Livro de Registro de Lugares como um dos bens imateriais reconhecidos como Patrimônio Cultural do Brasil.

Também de maneira semelhante à origem da feira de Caruaru, há registro de que a feira de Campina Grande surge no final do século XVIII em meio à formação do núcleo inicial da cidade. Esse fato foi considerado uma das justificativas para o seu registro como patrimônio cultural do Brasil. Além desse, citam-se outros fatores que justificaram seu registro, como a resistência ao fenômeno de globalização econômica, o fato de reunir produtos diversos para atender os consumidores, de ser um lugar de trabalho por gerações e gerações de trabalhadores e feirantes (filhos, netos, bisnetos, tataranetos), de possibilitar relações de fidelização e de se constituir objeto de produção escrita na literatura e na ciência (ARAÚJO, 2011).

A feira de São Joaquim, diferentemente das feiras acima descritas, ainda não obteve resposta do IPHAN para que se torne patrimônio cultural, e o pedido não foi feito pelo Poder Executivo Municipal. Trata-se de uma iniciativa tomada em 2005 pelo Sindicato dos Vendedores Ambulantes e Feirantes de Salvador (BA), cuja justificativa inicial para o registro foi a possibilidade de devolução do espaço onde acontece a feira, cedido aos feirantes por um período de 31 anos, para a Capitania dos Portos (Marinha), após a destruição da Feira de Água de Meninos em 1964.

Além desse aspecto, outros motivos arrolados para a inscrição da feira como patrimônio cultural intangível vão desde a venda de produtos litúrgicos da cultura afro-brasileira para a realização de cultos de religiões de matriz africana no Brasil e no exterior até a presença desse evento ou de seus elementos na literatura, em letras de música, em pinturas, fotografias e filmes, por exemplo.

A feira livre de São Joaquim é a mais importante feira soteropolitana e tem suas raízes no encerramento das atividades da Feira de Água de Meninos, ocorrido em 1964 por conta de um incêndio. Segundo Lima (2006), essa feira foi refeita por meio da organização de feirantes que perderam seus pontos de venda com o incêndio. A (re)criação da feira pode ser interpretada como uma necessidade de manutenção de suas atividades laborais, bem como de sobrevivência de milhares de produtores que criam interações socioespaciais e econômicas entre a capital baiana e diferentes localidades situadas no Recôncavo Baiano, além de possibilitar a venda de produtos a consumidores de diferentes bairros da cidade.

Trataremos a seguir das feiras livres de Capelinha e Alfenas, ambas reconhecidas como patrimônios culturais intangíveis de seus municípios. 
A feira livre de Capelinha (MG), registrada como patrimônio em 2009, ocorre aos sábados dentro do espaço físico do Mercado Novo e se constitui em evento de importância significativa na vida de relações produzida pela sociedade local. A maioria dos produtos que nela são comercializados é de produção familiar, embora se encontrem itens adquiridos em centrais de abastecimentos da região.

O envolvimento de diferentes segmentos dessa sociedade com a referida feira motivou o Conselho de Patrimônio Cultural do município a seguir as normas para protegê-la e solicitar o seu registro como bem imaterial, cujo processo é parte da política do governo municipal de preservação do patrimônio cultural local. Entre os bens relacionados como parte da feira como patrimônio citam-se o mercado que a hospeda, as barracas de venda e os conhecimentos tradicionais mobilizados na produção de doces e farinha de mandioca, entre outros.

O que ocorre na feira de Capelinha é o que ocorre em boa parte das feiras brasileiras. Logo, pode-se afirmar que é um lugar onde há

Cheiro das especiarias, do fumo, das frutas, das palhas dos cestos, dos doces, dos queijos, das ervas medicinais. Colorido dos legumes, das hortaliças, das suculentas frutas, das bijuterias, das roupas. Pessoas transitam em ruidoso barulho, examinam, pechincham, conversam ou simplesmente passeiam. Outras já têm suas barracas preferidas, conhecem o feirante de longa data e às vezes parecem mais amigos do que fregueses (PREFEITURA MUNICIPAL DE CAPELINHA, 2009, p. 50).

Já a feira livre de domingo de Alfenas (MG), registrada como patrimônio cultural intangível em 2019, existe há bastante tempo e se constitui em elemento de peso da cultura local. Sua origem seria bem anterior a 1960, conforme esclarece Eugênio (2019). Para ele, a feira já ocorria aos domingos nas imediações de um grande largo, hoje Praça Emílio da Silveira. O mesmo autor afirma ainda que ali se comercializava, entre os anos de 1908 e 1910, um significativo leque de produtos como toucinho, arroz, fubá, farinha, queijo, aguardente, entre outros, que eram vendidos sobretudo por comerciantes polivalentes e com pouca presença de mulheres feirantes.

A feira livre de domingo de Alfenas é organizada pela Associação dos Feirantes das Feiras Livres de Alfenas (AFFLA) em parceria com a Prefeitura Municipal e ocorre no entorno da praça Fausto Monteiro. Seus pontos de venda estão distribuídos basicamente em dois grandes setores. O primeiro situa-se na Praça Fausto Monteiro (lado norte), onde são encontrados pontos de venda de confecções, e o segundo ocupa o entorno (leste e sul) da referida praça, mas sobretudo na Rua Dr. Maciel Júnior, onde o consumidor pode encontrar frutas, cereais, pamonhas e queijo, entre outros itens de consumo.

Pelo visto, desde muito tempo a feira de domingo de Alfenas já atraía feirantes de outros municípios, pois, conforme ainda descreve Eugênio (2019), tendo como referência o período que 
vai de maio de 1908 a abril de 1909, comerciantes de Machado (8), Cabo Verde (4), Caldas (2), Pouso Alegre (2), Campanha (1) e Carmo do Rio Claro (1) passaram pela referida feira.

Considera-se que a importância histórica da feira de Alfenas, que existe a mais de 110 anos, e a permanência de muitas de suas características, como a comercialização de mais de um produto pelos feirantes, bem como a venda de produtos já negociados há mais de um século, como queijo, polvilho e café, entre outros, constituem parte dos motivos que justificaram o pedido de seu registro. Esse projeto foi iniciado pela $\mathrm{AFFLA}^{3}$, e os feirantes que a integram já haviam recebido ameaças de transferência da atividade para outras áreas da cidade desde a década de 1980. Uma dessas "ameaças" consistia em transferi-la para uma área situada ao sudoeste do local onde ela acontece atualmente, zona que se situa entre as ruas Alexandre Silveira Mariano e Silvano Brandão (PORTO, 2018).

Além desse motivo para o registro, a feira é reconhecida pela população como um bem de valor social e histórico, além de representar elementos da produção cultural local e regional por meio da culinária e dos artefatos locais nela comercializados. Ali são comercializados produtos encontrados em boa parte das feiras brasileiras, como legumes, frutas, verduras e confecções, por exemplo, mas há itens que o consumidor não está acostumado a adquirir em outras feiras livres, como pastel de fubá, doces com marolo, café moído no momento da compra, queijo fresco e farofa de feijão tropeiro preparada no local.

Além da importância cultural, a feira livre de Alfenas se constitui em evento e centralidade robusta no circuito espacial de vendas no Sul de Minas, atraindo feirantes e consumidores de localidades da região e mesmo de outros estados. Via de regra, a feira é um importante meio de difusão cultural, mas também de solidariedades de diferentes tipos, construídas entre feirantes, consumidores e todos os que a produzem pelo uso periódico do território, além de se constituir em espaço de encontro entre amigos, de passeio e de alimentação de seus utentes.

É importante ressaltar que a feira livre de domingo de Alfenas é parte de um subsistema municipal de compra e venda de mercadorias que integra o espaço banal da cidade, integrante do circuito inferior da economia. Fazem parte desse subsistema as feiras livres de sábado e quartafeira, que se realizava respectivamente na Avenida João Januário de Magalhães e na Praça Rachid B Bichara Saliba, e a feira agroecológica e cultural (Facu) que, até o início da pandemia da Covid-19, ocorria no campus sede da Universidade Federal de Alfenas.

\footnotetext{
${ }^{3}$ Intermediado pelo Conselho Municipal de Defesa do Patrimônio de Alfenas (Comdepa). 


\section{PATRIMONIALIZAÇÃO DE FEIRAS, TERRITÓRIO USADO E CONSTITUIÇÃO DE LUGARES}

Consideramos que o processo de patrimonialização de feiras é uma particularidade da formação socioespacial brasileira, formação essa entendida por nós como reflexo e condição de eventos, normas e situações produzidas em formações socioespaciais do centro do sistema capitalista. A título de exemplo, basta considerar que a maioria dos bens que primeiro se tornaram patrimônios mundiais pela UNESCO está localizada nesses países, onde também se concentra a maior parte dos registros, processo que passa a se manifestar um pouco mais tarde em localidades situadas em países periféricos.

O processo de patrimonialização global-local não se efetiva sem o uso do território (que é também território usado), sendo ele próprio movimento definidor de novos usos, bem como mantenedor de outros tradicionais. Partimos da ideia de Santos (1999) segundo a qual o território usado, sinônimo de espaço geográfico, corresponde a um território em mudança, a um território em processo, tomado nesse caso a partir de sua forma-conteúdo. Ele amplia a discussão ao afirmar que "o território usado são objetos e ações, sinônimo de espaço humano, espaço habitado" (SANTOS, 2005, p. 255). Daí se poder afirmar que o território é “o quadro da vida de todos nós, na sua dimensão global, na sua dimensão nacional, nas suas dimensões intermediárias e na sua dimensão local" (SANTOS, 1999, p. 19).

Mas quem usa o território|? Quais são os agentes que realizam o uso? O território é usado por empresas nacionais e multinacionais, por instituições políticas, culturais e financeiras, mas é também usado por mulheres e homens trabalhadores, imigrantes, vendedores ambulantes, feirantes enfim, por todos os homens e mulheres lentos que reproduzem suas vidas no espaço banal, espaço de todos, território de todos. Logo, o uso do território, além de ser definido pela implantação de infraestruturas, é também estabelecido pelo dinamismo da economia e da sociedade (SANTOS \& SILVEIRA, 2005) em diferentes escalas temporais e espaciais.

Cabe ressaltar que os usos do território se efetivam por meio da constituição de lugares, sejam eles produzidos pelas empresas ou pelos homens lentos. Neste último exemplo temos o território sendo usado pelas pessoas como direito existencial (SOUZA, 2019), logo pelos feirantes, consumidores e transeuntes que circulam livremente por ruas, praças e quarteirões onde as feiras ocorrem. Ou seja, identificamos nessa constituição uniões horizontais (em contraponto às uniões verticais realizadas pelas empresas) que poderiam ser ampliadas mediante formas próprias e novas de produção e consumo (SANTOS, 1999).

Nesse escopo se inserem as feiras livres como práticas tradicionais e econômicas, de uma maneira geral, e o processo de patrimonialização pelas quais um número ainda tímido delas vem sendo objeto de registros como patrimônios culturais imateriais. Em nosso entendimento, a 
realização de feiras é um bom exemplo da constituição de lugares, ao mesmo tempo que elas compõem o espaço banal nas cidades brasileiras. Segundo Santos (2006), o lugar, além de ser uma referência ao mundo, "é também o teatro insubstituível das paixões humanas, responsáveis, através da ação comunicativa, pelas mais diversas manifestações da espontaneidade e da criatividade" (p. $322)$.

Assim, a patrimonialização global como processo mundial se expressa no local, e no caso da patrimonialização de feiras ressignifica a constituição periódica de lugares, possibilitando que essa forma de comércio não seja "engolida" pelo comércio moderno, permanecendo como rugosidade de um período em que o tempo não era regido pela informação e pelo capital. Ou seja, além da necessidade de construir novas horizontalidades, conforme propôs Santos (1999), que de certa maneira vêm sendo tecidas ao longo dos últimos vinte anos por grupos, organizações e coletivos situados em diferentes cidades brasileiras, o registro de feiras livres como patrimônios pode se constituir, somando-se a outros processos de preservação do patrimônio cultural de interesse público, em uma das possibilidades de restabelecer a dignidade humana.

\section{CONSIDERAÇÕES FINAIS}

O processo de registro de feiras como patrimônios imateriais em geral, e da feira de Alfenas (MG) em particular, se justifica pelo interesse em preservar uma forma de comércio que resiste à chegada das grandes lojas de supermercados. Esse registro não altera o território usado semanalmente por feirantes e comerciantes nas cidades, mas possibilita adicionar a esse uso novos sentidos, práticas, ações etc. Podemos afirmar que se adicionam novos conteúdos à constituição semanal desses lugares. Além disso, tornar as feiras patrimônios pode ser um sinal de que há possibilidade de salvaguardar tradições, práticas e formas de comércio que existem há séculos na formação social brasileira, mesmo considerando que desse processo surgem contradições e conflitos.

Além disso, a patrimonialização de feiras livres possibilitará a manutenção da memória, da vida e de relações de solidariedade que se perderam em espaços modernos de consumo. Além desses avanços, esse processo assegurará a manutenção da memória dos pobres, bem como a do uso do tempo diferente do uso das empresas e das bolsas de valores, por exemplo. Ou seja, possibilitará a permanência das feiras como "rugosidades", como prática social e forma-conteúdo do passado, como espaço banal na cidade de Alfenas (MG) e naquelas onde as feiras livres foram registradas, ou poderão vir a sê-lo, como bens materiais intangíveis. 


\section{REFERÊNCIAS}

ARAÚJO, G. A. F. Continuidade e descontinuidade no contexto da globalização: um estudo de feiras em Portugal e no Brasil (1986-2007). 2011. 698 f. Tese (Doutorado em História Social) Faculdade de Filosofia e Ciências Humanas, Universidade Federal da Bahia, Salvador, 2011.

BATICINI, C. T.; ALVES, F. D. Alimentos identitários na feira livre de domingo em Alfenas-MG. In: MENEZES, S. S. M.; ALMEIDA, M. G. Vamos às feiras! Cultura e ressignificação dos circuitos curtos. Aracaju: Criação Editora, 2021. cap. 14, p. 427-450.

COSTA, A. A. Sucessões e coexistências do espaço campinense na sua inserção ao meio técnico-científico-informacional: a feira de Campina Grande na interface desse processo. 2003. 230 f. Dissertação (Mestrado em Geografia) - Centro de Filosofia e Ciências Humanas, Universidade Federal de Pernambuco, Recife, 2003.

COSTA, E. B. - Cidades da patrimonialização global: simultaneidade totalidade urbana totalidade-mundo. 1. ed. São Paulo: Humanitas, 2015. 480p.

EUGÊNIO, A. Verso e reverso da modernidade. A modernização em Alfenas na primeira república. 1. ed. Curitiba: Brazil Publishing, 2019. 213 p.

FERRETTI, M. M. R. Feiras nordestinas: estudos e problemas. In: FERRETTI, S. F. (Org.). Reeducando o olhar: estudo sobre feiras e mercados. São Luís: Edições UFMA. 2000. p. 35-66.

FREITAS, G. (Org.). 900 textos e documentos de História. Lisboa: Plátano, 1977. 156p.

IPHAN, MINC, PMC - FUNDAÇÃO DE CULTURA DE CARUARU. Dossiê Feira de Caruaru, Inventário Nacional de Referência Cultural. Fundação de Cultura de Caruaru/ PMC/IPHAN/MINC, 2006. Disponível em: http://portal.iphan.gov.br/uploads/publicacao/dossie9_feiradecaruaru.pdf. Acesso em: 10 jul. 2021.

IPHAN, MINC, PMC - FUNDAÇÃO DE CULTURA DE CARUARU. Dossiê Feira de Campina Grande. Patrimônio Cultural do Brasil. Inventário Nacional de Referência Cultural. Fundação de Cultura de Caruaru/ PMC/IPHAN/MINC, 2017. Disponível em: http://portal.iphan.gov.br/uploads/ckfinder/arquivos/Dossie_feira_de_campina_grande_para $\% \mathrm{C} 3 \%$ ADba.pdf. Acesso em: 10 jul. 2021.

JESUS, G. M. O lugar da feira livre na grande cidade capitalista: Rio de Janeiro, 1964-1989. Revista Brasileira de Geografia, Rio de Janeiro, v. 1, n. 1, p. 95-116, 1992.

LARA, C. B. Q. A cidade e o patrimônio: olhares sobre a feira livre de Dourados (1948-2016). In: ENCONTRO DE HISTÓRIA DA ANPUH/MS. 14., Dourados. Anais... Dourados: 2018. p. 1-17.

MOYSÉS, M. Circuito RAP do Distrito Federal: território usado e lugar. 2018. 224 f. Dissertação (Mestrado em Geografia) - Instituto de Geociências, Universidade Estadual de Campinas, Campinas, 2018.

MUMFORD, L. La ciudad en la historia. Sus orígenes, transformaciones y perspectivas. 1. ed. Logroño: Pepitas de Calabaza, 2012. 1158p. 
OLIVEIRA, K. C. A feira livre de domingo na cidade de Alfenas: pertencimento, resistência e padronização. 2015. 55 f. Monografia (Trabalho de Conclusão de Curso em Geografia) Universidade Federal de Alfenas, Alfenas, 2015.

PELEGRINI, S. C. A.; FUNARI, P. P. A. O que é patrimônio cultural imaterial. 1 ed. São Paulo: Brasiliense, 2008. 111p.

PIRENNE, H. História Econômica e Social da Idade Média. São Paulo: Editora Mestre Jou, 1963. 286p.

PORTO, G. C. S. Configuração socioespacial e inserção das feiras livres de Itapetinga-BA e arredores no circuito inferior da economia. 2005. 160 f. Dissertação (Mestrado em Geografia) Instituto de Geociências, Universidade Federal da Bahia, Salvador, 2005.

. Produção socioeconômica e inserção das feiras livres de Itapetinga-BA e arredores no circuito inferior da economia. In: SERPA, A. Cidade popular: trama de relações socioespaciais. Salvador: EDUFBA, 2007.

- Espaço e economia: dimensões da atividade comercial em Alfenas-MG. In: FERREIRA, M. M.; VALE, A. R. Dimensões geográficas no Sul de Minas Gerais. Curitiba: Appris, 2018. cap. 5, p. 129-151.

Gênese e dimensões da rede de vilas e núcleos de ocupação na Bahia no setecentos. GeoTextos, v. 14, n. 2, p. 89-115, 2018.

PREFEITURA MUNICIPAL DE ALFENAS. Feira Livre de Alfenas. Alfenas, 2019 (Dossiê, versão preliminar).

PREFEITURA MUNICIPAL DE CAPELINHA. Dossiê de Registro do Patrimônio Imaterial Feira-Livre de Capelinha. 2009. Disponível em: http://regiscap.com.br/wpcontent/uploads/2017/12/DOSSIE-DE-REGISTRO-DA-FEIRA-LIVRE.pdf. Acesso em: 10 jul. 2021.

SAES, A. M.; ROSA, E. R. Mercado pontual: atuação estatal na formação da feira de gado de Três Corações (1900-1920). Estud. Econ., São Paulo, v. 43, n. 4, p. 745-772, 2013.

SANTOS, J. E. Geografia econômica urbana: a Feira da Pedra e sua dinâmica urbana e regional. Natal: EDUFRN, 2017. 324p.

SANTOS, M. O Território e o Saber Local: algumas categorias de análise. Cadernos IPPUR, Rio de Janeiro, v. 13, n. 2, p. 15-26, 1999.

. O retorno do territorio. In: OSAL: Observatorio Social de América Latina. Año 6 no. 16 (jun. 2005). Buenos Aires: CLACSO, 2005.

2006.384p.

. A Natureza do Espaço: Técnica e Tempo. Razão e Emoção. 4. ed. São Paulo: Edusp,

O espaço dividido: os dois circuitos da economia urbana dos países

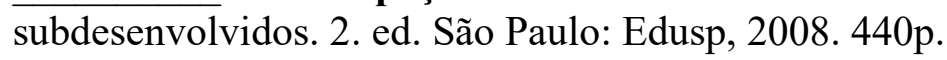


SANTOS, M.; SILVEIRA, M. L. O Brasil: território e sociedade no início do século XXI. 7. ed. Rio de Janeiro: Record, 2005. 473p.

SOUZA, M. A. Território usado, rugosidades e patrimônio cultural: ensaio geográfico sobre o espaço banal. PatryTer, v. 2, n. 4, p. 1-17, 2019.

STRAFORINI, R.; GARCIA, L; B. R.; CASTRO, J. F. M. Tropas e tropeiros em Sorocaba: a importância dos muares na produção de um espaço. GEOGRAFIA, Rio Claro, v. 23, n. 2, p. 7-34, 1998.

TREVISAN, E. A feira livre em Igarassu: uma análise a partir dos dois circuitos da economia; a convivência do formal e o informal. 2008. 119 f. Dissertação (Mestrado em Geografia) - Centro de Filosofia e Ciências Humanas, Universidade Federal de Pernambuco, Recife, 2008.

UNESCO. Convenção para a salvaguarda do Patrimônio cultural imaterial. Portal Iphan. Rio de Janeiro, 2003. Disponível em: portal.iphan.gov.br. Acesso em: 14 ago. 2021. 